\title{
Making Daily Determinations
}

\author{
Ajahn Amaro ${ }^{1}$ \\ Accepted: 16 October 2020 / Published online: 28 October 2020 \\ (C) Amaravati Publications 2020
}

Bring attention to this moment. How do you feel? What is the texture of this present reality? There is no right or wrong, good or bad in what we experience. Whatever the patterns of feeling and perception might be, they are brought into balance by our attitude towards them. The attitude of wise attention is the integrating, balancing agent. This is how the moment is held skillfully. If there is a grasping at or a pushing away of it, we are out of balance. The practice of attending, receiving, and fully participating in this moment brings a quality of balance and integration. However we might happen to feel, comfortable or uncomfortable, sleepy or wakeful, when mindfulness and wisdom recognize the qualities of this moment as simply patterns of nature, attributes of Dhamma, the effect is peace, ease and clarity.

\section{Mindfulness of the Posture}

As we go through the day, there are many different themes we can give to our practice, many different directions we can take in the efforts we are making. One helpful direction is to take this simple theme: notice what posture you are in at any one time, walking, sitting, standing, lying down. Simply notice the change from one posture to another. When you are walking, what is the intention as you walk across the room, down the hall, or along the path? Whenever there is walking, bring the attention to the feet. Throughout the day, develop that as a habit, as a skillful training. And as you bring attention to the feeling in the feet and the action of walking, reflect on this:

Excerpted from The Breakthrough by Ajahn Amaro, Amaravati Publications, 2016.

Ajahn Amaro

ajahn.amaro@gmail.com

1 Amaravati Buddhist Monastery, Great Gaddesden, Hemel Hempstead, Hertfordshire HP1 3BZ, UK
"Where do I think I am going? Is there anybody going anywhere?" Consider the reflection of Ajahn Sumedho's: "In actual fact there is no one going anywhere, there are just conditions of mind which are changing."

Take a simple theme like that to set as an intention at the beginning of the day. Notice whenever there is walking going on, and then hold that experience of walking within the context of wisdom. Notice the perception of the body walking, but ask: "Is there anybody going anywhere, or is there experiencing the conditions of mind coming and going and changing?" We take that simple, unremarkable, everyday act of walking, and we turn it into an occasion to awaken to Dhamma, to the fundamental reality that is the very fabric of this moment, of our lives and all things, the universal ordering principle of the mental, the spiritual and the physical.

\section{Developing the Perception of Anicca}

If we wish to take a different theme, there is the reflection on anicca, conscious development of the anicca-sañña and the perception of anicca. We can use the day to cultivate that perception, that habit of seeing all things as uncertain. Meet every perception, every judgement with a question: "Is this a sure thing? Not sure...." Develop this perception, this way of seeing; take this one simple exercise and cultivate it, develop it right where you're sitting, walking from room to room, eating breakfast, pruning the roses, cleaning the bathroom. Whatever it might be that we experience during the day, can we keep bringing this reflection to mind? Can we keep inquiring? Can we sustain interest in uncertainty? Notice how many things we judge, how many opinions we hold to be absolutely real: "This is wrong, this is right, this is good, this is bad, I approve, I disapprove, I like, I don't like, that's beautiful, that's ugly." In small and subtle ways, hundreds of times each day, the mind leaps into its perceptions and creates them as absolute values - remembering the past, expecting the future, planning, recollecting, approving, disapproving, hoping, fearing, 
regretting, rejoicing. When you think, "This was so wonderful”, ask yourself, "Are you sure?"

"That was awful."

"Are you sure?"

"I really hope. .."

"Are you sure?"

"I am really dreading...."

"Why is that? Are you sure it is going to be so bad?"

This is not just using anicca as a kind of repetitive mantra-anicca, anicca, anicca - but actually asking those questions, changing the view. When you bring that into being, when you change that view and really question: "Are you sure? Is that a sure thing?", see what happens in the heart when that uncertainty is entertained, when that flexibility is recognized. What happens in the heart? See how that catalyzes the liberating insight: "Of course all that arises passes away; all things are transient, empty, uncertain; this is the nature of all things all the time." In developing the anicca-sañña, we are bringing our view into accordance with reality, establishing Right View. The Buddha said (S 56.37): "Just as the lightening of the sky foretells the rising of the sun, so too Right View is the forerunner of all wholesome states." Just as the sky lightens when the dawn is about to come, Right View is the forerunner of everything wholesome within us.

The core of Right View is the recognition that all things are uncertain. By its very "thingness," there is uncertainty in every experience; there is change, transiency. We can take this uncertainty as a theme for the day, to make it a task: how often, how regularly can I remember to see the anicca, the uncertainty of all things, in my actions, my judgements, my plans, my memories? Can this be sustained and what's the effect? What happens in my heart? What's the result when that Right View is established? Explore. Then we can see for ourselves.

We don't need to make it too complicated or demanding for ourselves. We don't have to apply a whole range of different themes or reflections during the day. Take a single theme which appeals to you, which has meaning, is interesting and has value. Develop that one simple theme for a day; take it to heart, like noticing the act of walking or noticing anicca. Just take one simple discrete theme, and place it at the center of your concerns for the day and see what the effect is, how that changes you, what it brings.

\section{Listening to the Nada Sound}

A third suggestion might be to see how regularly and completely you can notice the presence of the nada sound, not only when everything is quiet but also when you are walking outside, while you are eating your food, brushing your teeth, pruning the roses. Can we notice it? Can we pick it up? Can we train ourselves to listen to it, to hear it in the midst of everyday activity? Even as we are listening to a Dhamma talk, can we hear it? Is it present? And in the same way we can consciously develop that, make it a theme, a center-piece of our efforts to see how often, how completely we can listen to the nada sound. What distracts us? How do we lose it? How long are the breaks between the time when we become distracted and the time when we recollect that we have forgotten to listen?

Take a simple theme like this, pick it up, work with it, develop it, and see what the results are. If we do train ourselves to attend to the inner sound, what is the effect of that as we go about our tasks and live our day? What is the effect of that inner listening? What are its blessings? What are the difficulties? What does it bring? Don't make things too complicated or over-involved. Take a simple theme like one of these or another of your own interests, consciously bring it up, and work with it for the day. In this way we develop skills and begin to understand what is helpful, what is obstructive, what is difficult, what is easy, what brings benefit or causes confusion and complication. We see for ourselves. We learn for ourselves. This is really the only effective kind of learning we can do. Hearing and gathering information from outside is one thing, but it is the hands-on tasks we do ourselves, and the learning which happens within us that comes from them, which bring about real changes.

\section{Perfect in Knowledge and Conduct}

In all these different approaches to Dhamma practice, there is a blending of two particular qualities, awareness and action. When we recite the attributes of the Buddha, one of them is vijja-carana-sampanno. Vijja is awakened awareness, knowing. Carana is conduct, action. Sampanno means to be accomplished or consummately expert, fully perfected. Vijja carana-sampanno means one who is perfect in knowledge and conduct or one whose actions and wisdom faculty are perfectly fused. Vijja is the transcendent, unattached, unentangled element, which has completely gone beyond. Carana is the element which is perfectly attuned, completely in accord with life, participating, belonging to the world, fully embodying the world of the four elements and the six senses, fully attuned to the material reality and the laws of the natural world; immanently present, utterly here.

So in these kinds of practices - developing mindfulness of the body, listening to the nada sound or whatever simple practice we might choose to follow - there is attention to the action (carana: the quality of attunement and participation), and there is the quality of awareness (vijj $\bar{a}$, transcendent knowing) which lets go of everything. These two work together, that which is fully aware of what is being done, and the care with which things are being done, vijja and carana. 
Vijjā: that which is totally transcendent, which lets go and is unattached to all things. Carana: that which is fully attuned, participating, belonging, which loves the world and holds it skillfully. The balancing and integrating of these two qualities is the Middle Way itself.

Many years ago Luang Por Chah said to the newly ordained Bhikkhu Sumedho, "Sumedho, you must find it confusing because Dhamma is all about letting go, and Vinaya (the monastic discipline) is about holding on." And, he said, "Yes, actually I do."

The Dhamma side of practice is all about relinquishing, abandoning, letting go, non-attachment. The Vinaya side of the monastic training is the 10,000 do's and don'ts of looking after your robes, how to eat and how to relate to people and property. When Luang Por said that, Ajahn Sumedho thought: "Okay, now he is going to explain how that happens." But all Luang Por Chah said was "When you figure out how those two work together you will be just fine."

So it's a conundrum. How do the immanent and the transcendent co-exist? How do vijjā and carana work together? But they do, and this is the mysterious nature of the Middle Way: how to care about every detail but be totally unburdened; how to honor and respect every convention, how to pay heed to every nuance of right and wrong with sincerity and integrity, and yet be totally unattached at the same time. How do we do that? Yet we can do it. "To care and not to care" as T. S. Eliot put it, without hypocrisy, without confusion - we can do that. This is a skill we have the opportunity to develop, the skill of being sincere in every effort, but creating no stress about what we do.

When you discover that mysterious balancing point, that Middle Way, that wonderful middleness which is called tatramajjhatata - "in-the-middle-of-that-ness" - when you discover that wonderful balance, notice how it feels. Let it be fully acknowledged, fully attended to. Notice the quality of that balance. We don't have to create a concept about it. It is like learning to ride a bicycle; it is not a concept, but a wholebody learning. The Middle Way is not an idea; it is a mode of being. So when you find those moments of balance, let yourself be fully aware of that feeling, fully attentive to that feeling. What does that quality of balance feel like? How is it? Let it be fully known.

Publisher's Note Springer Nature remains neutral with regard to jurisdictional claims in published maps and institutional affiliations. 